Article

\title{
The Risk of Residential Peak Electricity Demand: A Comparison of Five European Countries
}

\author{
Jacopo Torriti \\ School of the Built Environment, University of Reading, Whiteknights, PO Box 219, Reading RG6 6AY, UK; \\ j.torriti@reading.ac.uk
}

Academic Editors: Xudong Zhao and Yanping Yuan

Received: 29 November 2016; Accepted: 15 March 2017; Published: 19 March 2017

\begin{abstract}
The creation of a Europe-wide electricity market combined with the increased intermittency of supply from renewable sources calls for an investigation into the risk of aggregate peak demand. This paper makes use of a risk model to assess differences in time-use data from residential end-users in five different European electricity markets. Drawing on the Multinational Time-Use Survey database, it assesses risk in relation to the probability of electrical appliance use within households for five European countries. Findings highlight in which countries and for which activities the risk of aggregate peak demand is higher and link smart home solutions (automated load control, dynamic pricing and smart appliances) to different levels of peak demand risk.
\end{abstract}

Keywords: demand management; European Supergrid; peak loads; residential electricity demand

\section{Introduction}

For decades energy regulators have focused on optimal market-based tools to facilitate access to energy supply in order to meet demand and reduce costs. The emphasis has mainly been on liberalisation and removal of market barriers. More recently, the debate around climate change has emphasised the role of the risk of peak demand in balancing electricity demand and supply, as excessively high energy demand brings about significantly negative environmental and economic impacts. At times of peak demand, increasing the output of gas-fired generators, for example, may not be enough. Electricity price spikes occur frequently when demand is very high because there is extremely high price volatility due to the higher volume risks. In cases when at peak time less efficient or higher cost generating units are used to meet higher demand, electricity prices in wholesale markets could fluctuate from less than four euro cents per $\mathrm{kWh}$ to as much as 25 cents per $\mathrm{kWh}$ on several days of the year [1].

Whilst a vast amount of data is available with regard to the risks associated with generation, transmission, distribution and supply of electricity, no research has endeavoured to model the risk of aggregate peak electricity demand at the European level. Residential electricity demand profiles are highly correlated with the timing of appliance use. At the time of occupancy, consumers are likely to be involved in activities that necessitate consumption of electricity. This paper makes use of occupancy time-series data from the Harmonised European Time-Use Survey (HETUS) Database with the aim to assess the risk of aggregate peak demand in European electricity markets. To this end, the risk of aggregate peak electricity demand is assessed in terms of changes in occupancy and time-use of appliances in five European countries.

The paper introduces the issue of risk of aggregate peak electricity demand in European electricity markets (Section 2). It presents the methodology for assessing the risk of aggregate peak demand (Section 3). It then presents the findings on the assessment of risks of aggregate peak demand (Section 4). It discusses the relevance of time-use data in relation to the risk of peak demand (Section 5). The paper concludes by discussing the implications of this work for future electricity markets (Section 6). 


\section{The Risk of Aggregate Peak Demand in European Electricity Markets}

\subsection{European Electricity Markets}

For the greatest part of the last century European electricity markets operated as separate national or regional networks. This is because of the historical role of national monopolistic energy utilities, which developed grids under the assumption that each country could meet its energy demand through national supply and imports. The slow but inevitable liberalization of European energy markets over the last ten years has dissolved the traditional nation-state economic energy model. Although full market liberalization still presents heterogeneous features [2] and arguably has not been completely achieved [3], the three European Union packages on the liberalization of energy markets have marked the progress towards the highest level of integration of energy markets ever experienced in Europe [4]. The formal integration of energy markets is also marked by the creation of new institutions, like the Agency for the Cooperation of Energy Regulators (ACER)—a Europe-wide supranational regulator which aims to support market integration, advise national energy regulators and monitor the progress of market co-operation.

In addition to the institutional integration of electricity markets, new developments in renewable energy have led several Governments to consider a future European Supergrid, which will consist of an integrated power system network, where electricity demands from one country will be met by generation from another country [5]. This will be achieved through building new cross-border connections that will improve current electricity transmission and distribution systems, which were designed over 40 years ago. For instance, UK interconnector projects under investigation include two interconnectors with Norway as part of the North Seas Countries' Offshore Grid Initiative additional interconnection with France, as well as Iceland, Ireland, Denmark and Spain. Interconnectors are supposed to guarantee security of supply at all times by transporting large power flows across regions.

\subsection{The Risk of Aggregate Peak Electricity Demand}

Technology optimists argue that in the European Supergrid the risk of power cuts will be mitigated by the diversification of electricity generation mixes, from solar to wind to nuclear [6]. However, for a correct balancing between supply and demand to function, the implications of aggregate demand need to be explored. Congestion associated with peak demand is a problem for trading electricity across borders not only because of the risks of blackouts (i.e., excessive demand) [7], but also because intermittent renewable sources of energy in one Member State may be generating so much electricity that the transmission capacity to other countries is exceeded (i.e., excessive supply). Congestion costs across the most congested interconnectors in Europe are currently estimated to be $€ 1.3$ billion each year [8].

The source of the problem rests in the missing connection between electricity tariffs and actual electricity costs [9]. Most of the retail electricity tariffs in Europe do not reflect the time variation in the cost of supply. As a result, customers are not provided with the appropriate price signals to promote efficient electricity consumption and may over-consume electricity during expensive peak periods and under-consume electricity during inexpensive off-peak periods. The lack of any price signalling prevents customers to operate in a responsive manner in the retail market. The image of a supermarket without price labels on the products can figuratively explain the lack of price signals in electricity markets. One of the unintended consequences of the lack of information on prices is that consumers might simultaneously opt for sub-optimal choices. In energy economics terms, the risk of aggregate peak demand corresponds to the sum of simultaneous sub-optimal decisions taken by multiple customers to consume electricity when it costs the most. For European electricity markets, the scale of aggregate risk partly depends on the probability of individuals entering and leaving the household at the same time in different countries. 


\section{Methodology}

\subsection{Review of Methodologies Modelling Energy Demand Based on Time-Use Data}

Some of studies attempting to model the timing of energy demand from time-use data make use of existing national surveys. Time-use data have been simulated using probability, stochastic modelling and the Markov chain technique [10]. For instance, Richardson et al. deployed bottom-up models for UK electricity demand starting from the UK Time-Use Survey [11]. They generated occupancy data for UK households based upon surveyed time-use data describing what people do and when. They made use of a probabilistic approach to infer how many other occupants enter or leave the household between a 10-min interval and the next one.

The generation of occupancy data has been used by the same researchers as a starting point for their electricity demand simulation, which covers major household appliances [12]. In this case, the stochastic modelling approach (also known as the Markov chain technique) is validated by actual data from electricity users.

Similarly, the model by Widen and Wäckelgård simulates household activities based on time-use data [13]. The timing of electricity demand is derived from time-use patterns. The household activity simulation is produced on the basis of non-homogeneous Markov chains which reduce the time-use dataset to 1-minute intervals [14].

In another study, a Europe-wide model of occupancy was developed to identify occupancy peaks in 15 European countries. Europe-wide occupancy and time-related electricity demand curves were constructed for TV and video watching activity. National variance in occupancy levels at the aggregate European level profiles were assessed [15].

Unlike previous studies, the risk model presented in this paper makes use of the concept of aggregate peak demand risk to assess in which periods of the day the use of electrical appliances may cause congestions to the power network. In order to make the study as relevant as possible, another time-use database is used. The HETUS database has the merit of relying on appliance-specific data from different countries.

\subsection{HETUS Database}

A subsection of the HETUS Database is derived based on household panel surveys in five European countries, i.e., Norway, Germany, Italy, Bulgaria and the UK. The database consists of randomly sampled households. Overall the HETUS Database provides 1,260,000 10-min interval data entries from 8750 comparable individuals across the 5 selected countries.

The dataset relates to data collected between 2001 and 2005. More specifically, the years of data collection are as follows: Bulgaria from 15 October 2001 to 15 October 2002; Germany from April 2001 to March 2002; Italy from 1 April 2002 to 31 March 2003; Norway from 20 February 2000 to 19 February 2001; and UK from January to December 2005. It is publicly accessible through Eurostat (www.ec.europa.eu/eurostat/cache/metadata/en/tus_esms) and the Centre for Time Use Research at the University of Oxford (www.timeuse.org/mtus/surveys/GBR/2991). A 24-h time-use diary item was included as part of the questionnaire. Appendix A provides a detailed description of the time-use questions which were included in the diary.

Time-use surveys are the main source of data for knowing when people are either inside or outside the household. The time spent in the household creates the necessary conditions for using electricity. The time spent outside the household reduces, but does not rule out the possibility of household-related electricity consumption. Notable exceptions consist of appliances running cycles set on timers for non-occupancy periods and base-consumption, i.e., the standby power, which in European households is typically around $0.05-0.2 \mathrm{kWh}[16]$.

Some of the time-use data can be associated with the timing of electricity consumption. This mainly depends on how appliance-specific the diary entry is. For instance, for the entry called "TV and Video watching" it is possible not only to derive the timing of electricity demand, but also, 
with some approximation about the average efficiency of the TV and video sets, the actual physical demand in kWh. However, diary entries like "household work" are not appliance specific, making it difficult to associate the timing of that activity with electricity demand.

In order to construct a model which identifies the risk of aggregate electricity demand, some household activities which can be associated with the use of electrical appliances were identified. Those activities in Appendix A which are coded from 2, 3, 4, 5, 6, 7, 21, 22, 23 and from 28 to 33 provide inputs to the risk model explained below. The risk calculation is based on power demand not defined by activities (i.e., cold appliances, modelled as a base load); power demand constant during activity (i.e., cooking, ironing, cleaning, use of TV, audio appliances and computer); power demand constant after activity (i.e., dish-washing, washing and drying); and activities with time-dependent power demand (i.e., lighting with power varying with time dependent on day lighting levels). Appendix B provides descriptive statistics (Values Are Mean Minutes per Day per Person) for different activity codes.

\subsection{The Risk Model}

The risk model focuses on how often the use of electrical appliances exceeds a certain value $\omega$, which corresponds to a fixed level of supply that the European Supergrid can tolerate. In the following, $Y_{1}, Y_{2}, Y_{3}, Y_{4}$ and $Y_{5}$ are the total share of active use of electrical appliances by country, and $A_{K}$ is the total amount for the European Supergrid.

The distribution function $Y_{1}, Y_{2}, Y_{3}, Y_{4}$ and $Y_{5}$ is denoted by $F$. Assuming that appliance use can only be positive, means that $F(0)=0$ and that $F(y)<1$. In addition $\ddot{F}(y)=1-F(y)$ for $y \geq 0$, which represents the tail of $F$. In order to determine where the share of active use of electrical appliances exceeds a fixed supply $\omega$, this time point is determined by

$$
X(\omega)=\min \left\{Y_{k}>\omega\right\} .
$$

The minimum is set as the minimum over the countries, so that, when this condition is satisfied all countries have a consumption beyond the threshold omega. Setting

$$
\rho=P(Y>\omega)=\ddot{F}(\omega)
$$

The random variable $X(\omega)$ is distributed according to the risk parameter $\rho$. This means that the probability that $X(\omega)$ takes the value $\mathrm{k}$ is given by

$$
\mathrm{P}(X(\omega)=k)=(1-\rho)^{k-1} \rho
$$

which is the probability of a geometric random variable and could be interpreted as the probability to have a success (to be over the threshold) after $(k-1)$ failures. In other words, this stands for the probability that in $k-1$ countries there is no excess of appliance use compared with fixed supply, but in the European Supergrid there is still an excess.

The risk of aggregate peak demand can be represented as:

$$
\sum_{i=1}^{k} i P(X(\omega)=k)=\rho \sum_{i=1}^{k} i(1-\rho)^{i-1}=1 /[P(Y>\omega)]=1 / \ddot{F}(\omega)
$$

The $\omega$ values are obtained from electricity supply flow data from ENTSO-E Network report on Capacity Allocation \& Congestion Management [17].

The different time zones of the 5 countries were measured as Central European Time (CET). This means that the timing of consumption in Bulgaria and UK were adjusted to CET. For instance, time-use survey data at 18:00 (Greenwich Meridian Time) in the UK is shifted to 19:00 (CET). A distinction is made between morning peak period (from 7 a.m. to 9 a.m. CET), evening peak 
period (from 6 p.m. to 10 p.m. CET). Consequently, the risk of peak residential electricity demand is divided into baseline risk, representing all day, including peak periods, morning peak risk, evening peak risk and non-peak risk, which consists of daytime difference between baseline risk and the two peak risks.

Table 1 shows the typical electricity load for each appliance. The electricity loads that may be associated with preparing food or drink show that, if using an electrical appliance, the load is around $2 \mathrm{~kW}$ if one of these appliances is used. Not all households own each of the electrical appliances, but notable high ownership of appliances is kettles, vacuums, TV and TV receiver boxes.

Table 1. Time-use activities and associated appliances, including electrical load and proportion of dwellings with appliance.

\begin{tabular}{cccc}
\hline Activity & $\begin{array}{c}\text { Employed Electricity } \\
\text { Appliances }\end{array}$ & $\begin{array}{c}\text { Typical Electrical } \\
\text { Load (kW) }\end{array}$ & $\begin{array}{c}\text { Proportion of Dwellings } \\
\text { with Appliance (\%) }\end{array}$ \\
\hline \multirow{3}{*}{ Preparing food and } & Hob & 2.40 & 46.3 \\
washing the dishes & Oven & 2.13 & 61.6 \\
& Microwave & 1.25 & 85.9 \\
& Kettle & 2.00 & 97.5 \\
Washing & Dish washer & 1.13 & 33.5 \\
\hline \multirow{2}{*}{ Cleaning } & Electric shower & 9.00 & 67 \\
& Central heating pump & 0.60 & 90 \\
\hline \multirow{2}{*}{ Washing clothes } & Vacuum & 2.00 & 93.7 \\
& Tumble dryer & 2.50 & 41.6 \\
& Washing machine & 0.41 & 78.1 \\
Watching TV and & Washer dryer & 0.79 & 15.3 \\
listening to the radio & Iron & 1.00 & 90 \\
\hline Using computer & TV & 0.12 & 97.7 \\
\hline
\end{tabular}

\section{Assessing Aggregate Peak Electricity Demand Risk}

\subsection{Use of Electrical Appliances}

Figure 1 shows the percentages of active use of electrical appliances by European residents against time. Figure 1 does not take into account population, but simply the percentage of households with at least one active tenant involved in activities which require the use of electrical appliances.

Figure 1 shows extremely low levels of electrical appliance use during night hours and very high levels of appliance use during meal periods for Central European Time (CET). The move of all time-use data to CET may underpin some of the variations between CET countries (Italy, Germany and Norway), and the UK, which is one hour behind CET and Bulgaria, which is one hour ahead of CET.

Figure 2 illustrates the break-down of the time spent in each country on activities which involve the use of electrical appliances. The baseline for this measurement varies depending on how many hours per day are spent in overall activities.

The category "leisure at home" involves activities like "watching TV/Cable/Satellite TV"; "watching videos/laser disks"; and "listening to radio, CD, cassette". Activities like "reading newspapers, books, magazines" and "being visited by friends or relatives in own home" were not included as not directly related to any appliance use. The use of lighting is excluded from this analysis. "Leisure at home" takes about $38 \%$ of the time spent in activities which involve the use of appliances in Bulgaria, Germany and the UK. The category "at home" includes "care of own children or other adults in own home"; "cleaning house, tidying, clothes washing, ironing, sewing etc."; and "maintenance, odd jobs, DIY, gardening, pet care". The "at home" category takes up between $26 \%$ and 39\% of appliance-related time in households in the UK, Norway and Germany. In Bulgaria and 
Italy the category "food", which mainly stands for cooking and food preparation represents $26 \%$ and $37 \%$ of time in Bulgaria and Italy respectively. "Personal hygiene" relates mainly to washing, which is considered here because of the high penetration of combi-boilers in the sample countries [18]. This category is limited to two percent to five percent of overall appliance time use.

Figure 3 illustrates the impacts of active electrical appliance users when scaling up findings by population in the five European countries. Larger countries like Germany, Italy and the UK are more likely to contribute to the risk of aggregate peak demand than Bulgaria and Norway. These absolute figures are only indicative as they do not take into account the types of buildings within a country, nor the number of occupants. Additionally, for the sake of simplification, it is assumed that: (i) appliance efficiency are very similar throughout these five countries (due to implementation of EU directives on energy efficiency); and (ii) the location of generation is consistent with demand in a European smart grid. Although higher electricity demand may increase during time periods with extreme temperatures (too low or too high), due to use of appliances for heating, cooling and ventilation, this paper does not take into account temperature variations. The two grey shaded areas represent the morning peak period (from 7 a.m. to 9 a.m.) and the evening peak period (from 6 p.m. to 10 p.m.).

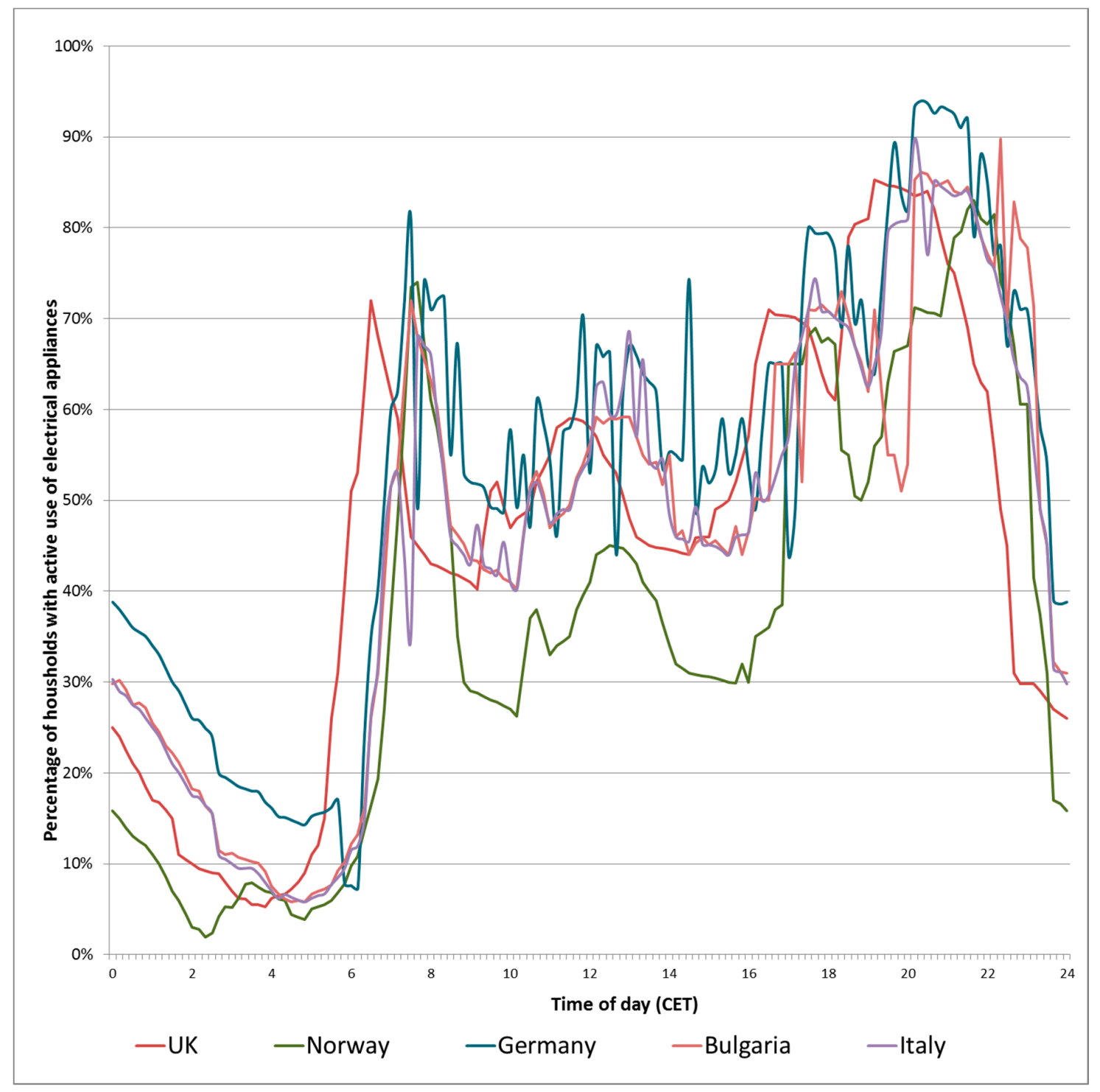

Figure 1. Active use of electrical appliances by residents in five European countries. 


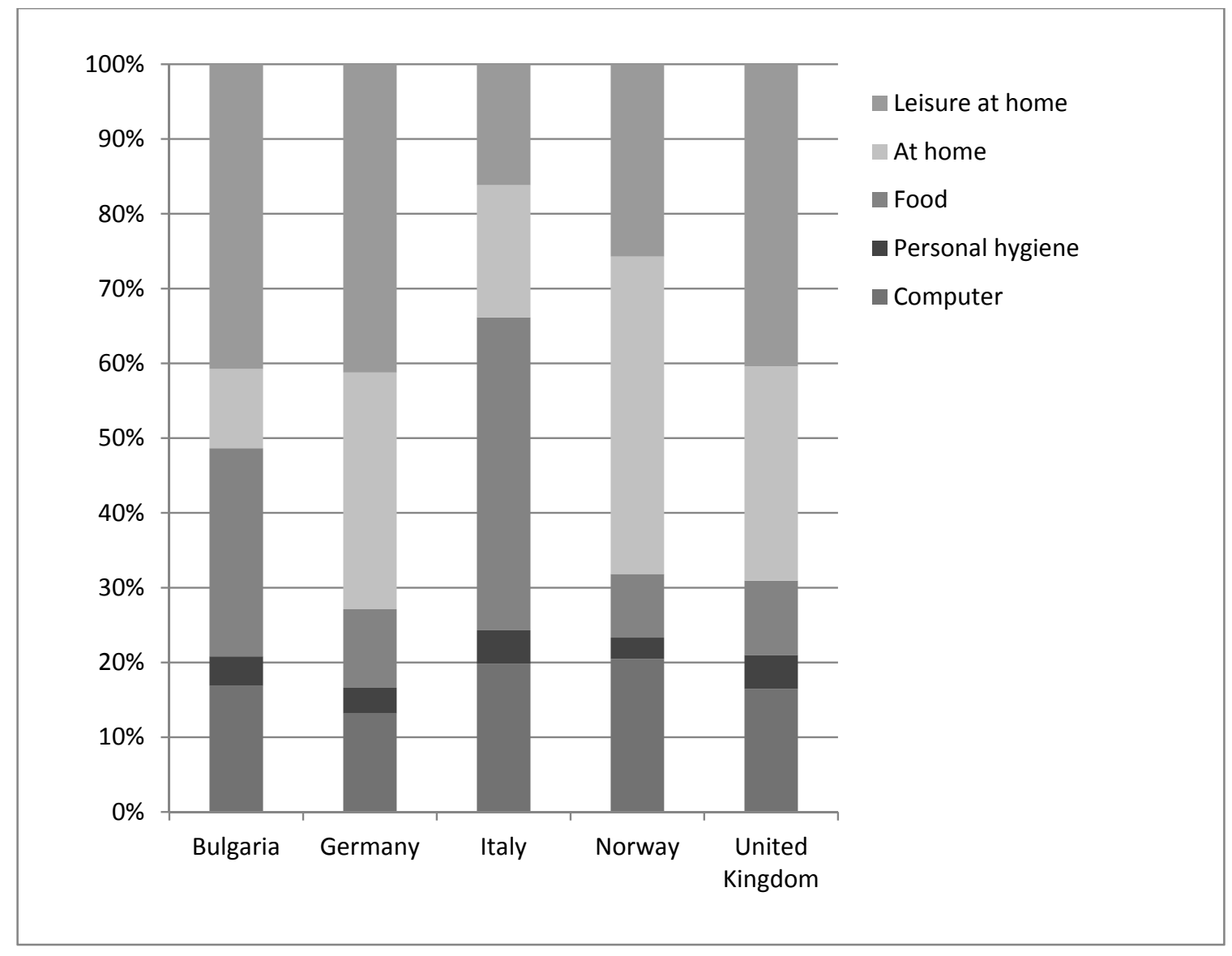

Figure 2. Share of time-use activities related to appliances in the household.

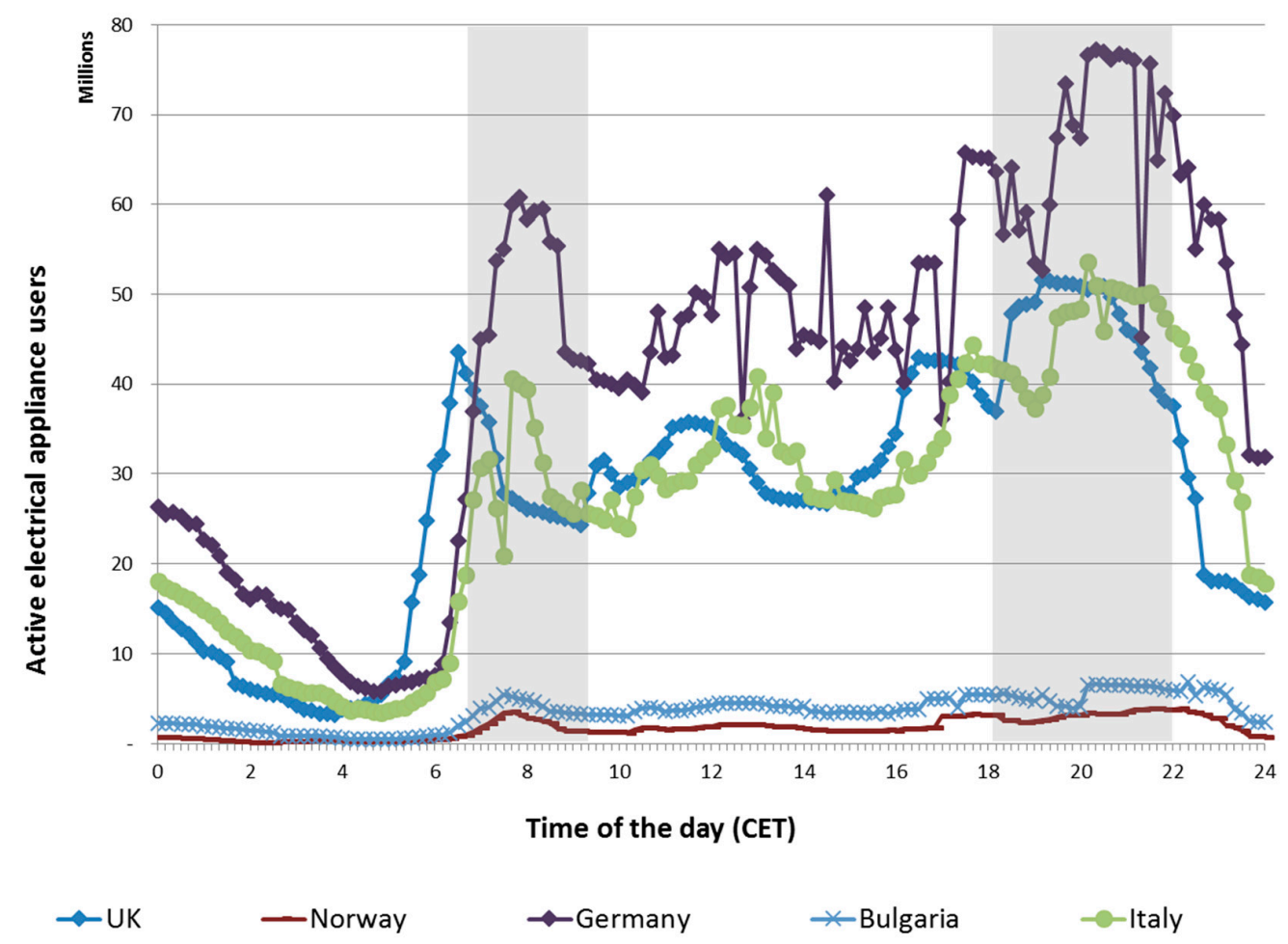

Figure 3. Active electrical appliance users. 


\subsection{Risks}

Baseline risks are assessed using a bottom-up approach from all time intervals. Figure 4 presents the risk of aggregate peak demand in terms of baseline risk, morning peak risk, evening peak risk and non-peak risk in the five countries. The findings in Figure 4 are presented as relative figures. This means that the size of the country is controlled in order to understand the impact of the individual average household electrical appliance use on peak risks. For instance, in Bulgaria the high peak morning risk and peak evening risks combined $(\rho=0.168)$ imply that electrical appliance use at peak time yields potentially significant demand and supply balancing problems on the national transmission grid as well as local distribution networks. The country with the largest baseline risk per household is Bulgaria $(\rho=0.194)$ followed by UK $(\rho=0.165)$. Unlike Bulgaria, a significant share of risk is represented by baseline risk. This means that, in the UK, base consumption is higher than in other countries, including for night time. Conversely, in Bulgaria much of the baseline risk is explained by morning and evening peaks and non-peak risk in the daytime. The average household in Italy, Germany and Norway has similar characteristics in relation to the risk of peak electricity demand.

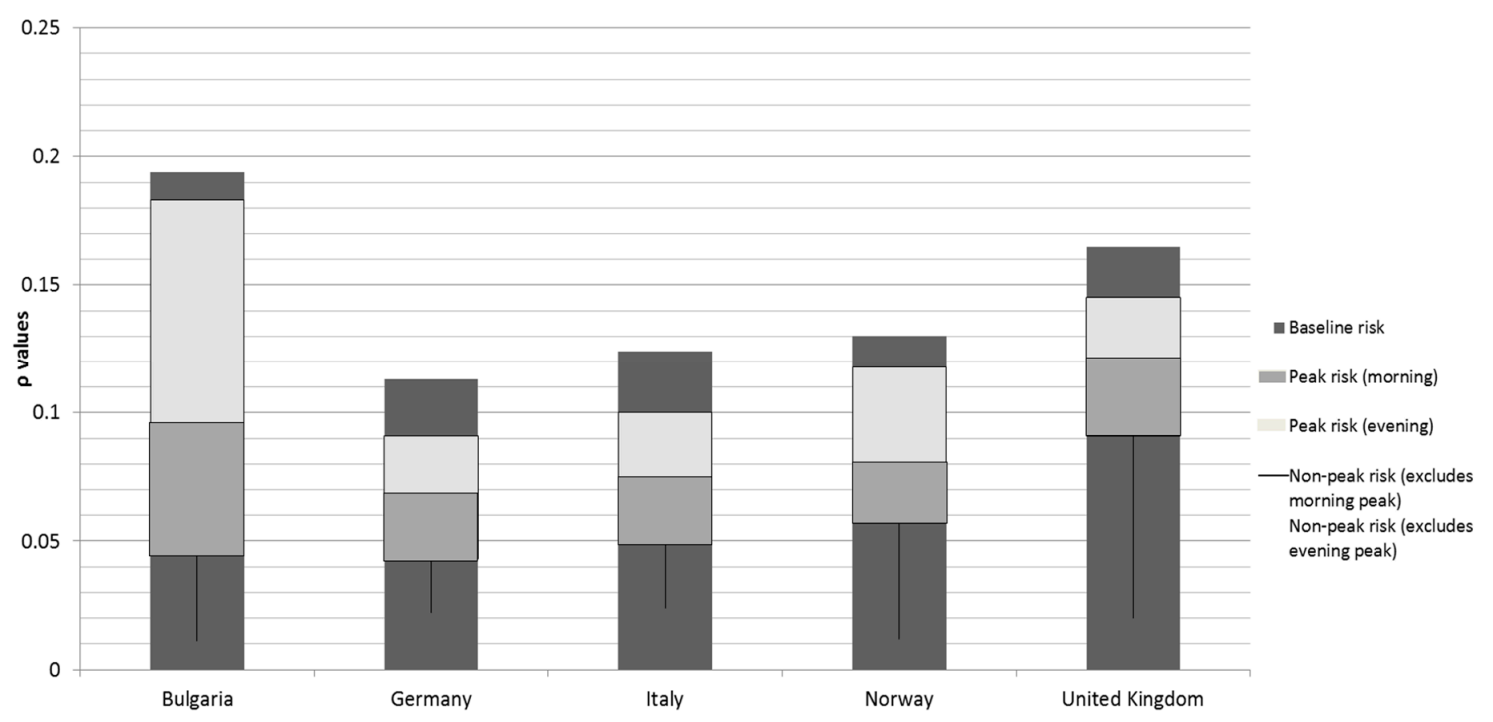

Figure 4. Baseline risks, peak risks and non-peak risks (per household).

Figure 5 presents the overall country contribution to a hypothetical European Supergrid in terms of aggregate risk of peak electricity demand. The size of the country obviously matters, although the distribution of risk in terms of baseline risk, peak risk and non-peak risk is maintained. This means that peak risks represent a very significant role, i.e., between $23 \%$ and $89 \%$ of overall $\rho$ values. The UK yields the largest risk portion of risk $(\rho=0.099)$ followed by Germany $(\rho=0.093)$, Italy $(\rho=0.074)$, Bulgaria $(\rho=0.015)$ and Norway $(\rho=0.0062)$. One of the most obvious implications of these findings is that any action aimed at addressing the risk of aggregate peak electricity demand for the European Supergrid should take into account larger member states first. What these actions might be will be discussed in the next section. 


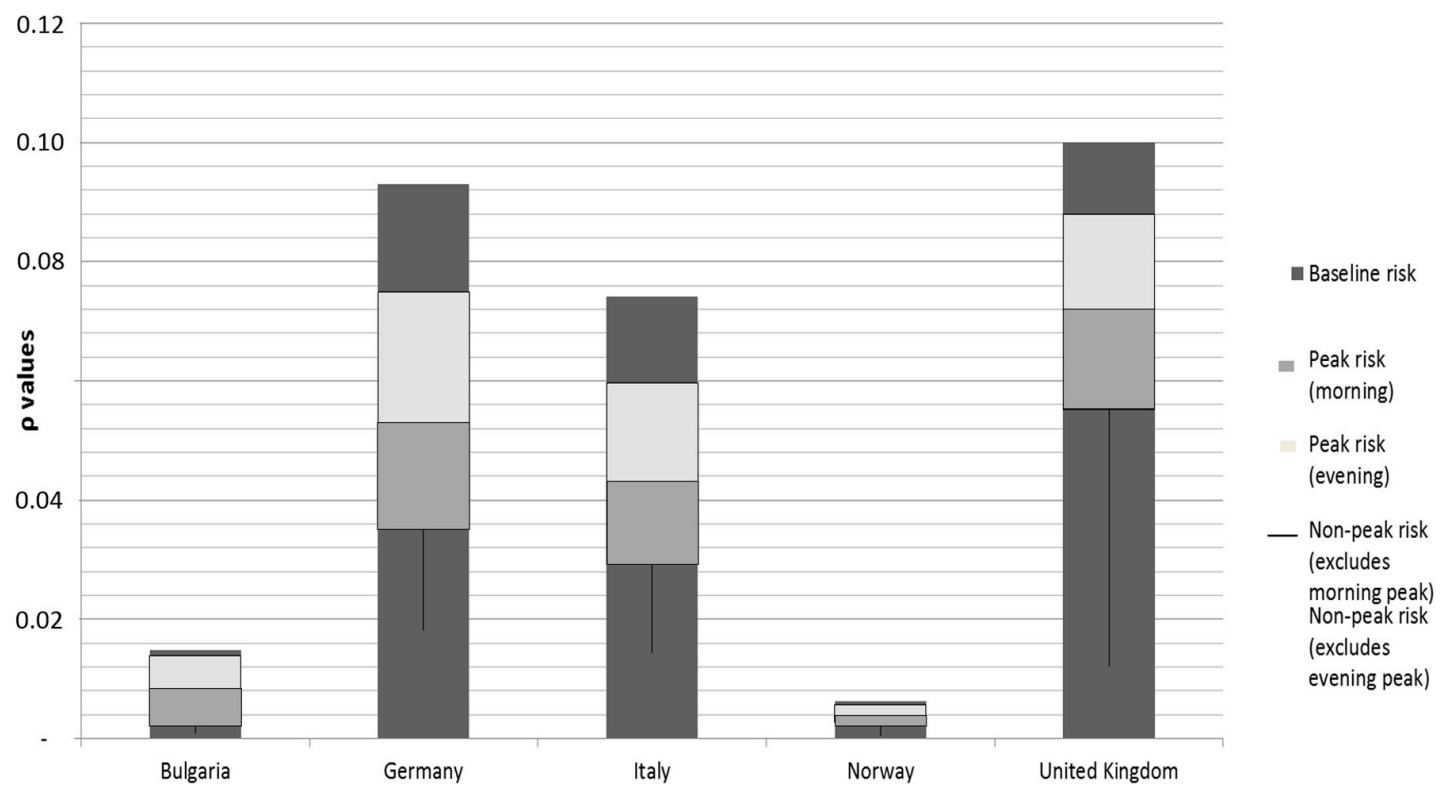

Figure 5. Overall country contribution to aggregate risk of peak electricity demand.

\section{The Relevance of Time-Use Data in Relation to the Risk of Peak Electricity Demand}

The findings of this study, combined with other research on occupancy reviewed in Section 3.1 show that there are at least eight issues that impact the measurement of the timing of electricity demand through time-use appliance data.

First, time-related data are not significant for individual users. They become significant only for aggregate users. For this reason, large datasets (like the national time-use surveys) are more significant than detailed individual user ethnographic data on e.g., causal relations for particular timing of activities.

Second, in order to address the issue of peak congestion, EU policy-makers have started rolling-out smart metering devices. Smart meters are two-way communication systems which enable immediate reading of the physical $(\mathrm{kWh})$, environmental $\left(\mathrm{CO}_{2}\right)$, and economic (USD) impacts of energy consumption. Smart meters are being deployed in most European countries with a view to increase consumer awareness and reduce overall energy consumption. Providing feedback on smart meters devices has been shown to reduce electricity consumption by $6 \%-10 \%$, though there is debate on the accuracy and applicability of this figure $[19,20]$. However, smart meters per se do not prevent peak loads as they do not facilitate shifts in energy consumption [21]. As stated in Section 2.2, the lack of time-variable electricity tariffs may be a barrier to customers reducing demand at peak price times. While many utilities across Europe have simple "time of use" pricing strategies whereby a second meter records "night usage" and the user is charged at a reduced rate for this, some utilities have proposed a more detailed breakdown with the following order of prices off-peak (night), peak-morning, shoulder, peak-evening, shoulder, off-peak (night). The results in Figure 1 seem to suggest that this would be a sufficient approach for all countries studied without needing a detailed breakdown (depending on the flexibility of the energy consumers).

Third, time-related appliance data are representative of average days, typically weekdays, where societal constraints standardise routine and practice of everyday life. However, some of the most sizeable peak events take place on non-average days due to either particular weather conditions-e.g., a very cold winter day in Northern Europe or a very hot summer day in North America, where the use of air conditioning is diffused—or rare public events—e.g., a football final or a royal wedding.

Fourth, large time-use surveys are conducted very seldom. For example, the last nation-wide UK time-use survey was carried out in the year 2000. Whilst most appliance-use and mobility patterns may not have changed dramatically, the evolution in the use of electronic devices calls for a careful 
consideration of "old" appliance use data in relation to "new" timing of energy demand. This study addressed this problem by relying on the HETUS dataset for five countries.

Fifth, the comparison of time-use data among national datasets emphasises high similarities. These could be explained through macro socio-economic phenomena, such as globalisation. Notwithstanding the reasons, the high level of similarity in occupancy patterns demonstrates that, at least in developed countries, the timing of occupancy is less variable than other factors that influence energy consumption (e.g., weather, appliance design, etc.). This partly explains what energy economists define as the rigidity of the residential demand curve against time and price.

Sixth, occupancy profiles can only be regarded as proxies for time-related energy demand curves. This is partly because some human activities in national time-use surveys cannot be associated with appliance consumption and partly due to the fact that some energy services (e.g., heating, boilers) can run in the absence of occupants.

Seventh, whilst occupancy for single-person households is relatively easy to forecast, for multiple-person households the flow inside and outside the household is much more difficult to model. Attempts to model every other occupant stochastically have the merit of being comprehensive at the expense of increasing the error between occupancy profiles and timing of energy demand. In this paper the presence of at least one person in the household is considered to have effects on residential electricity demand.

Eighth, since the risk of aggregate peak demand depends on the size of the country, in principle it might be possible for future research to draw a priority list of possible interventions. This could consist of various demand side response options, including programmes, technologies and tariffs. What is more, future research might be able to construct a Marginal Abatement Cost curve for demand side response options. This would be in the same vein as other Marginal Abatement Cost curves associated with the monetary benefits of reducing the risk of climate change [22].

\section{Conclusions}

This paper shows dissimilarities in $\varrho$ levels across the five different analysed countries. For instance, the average household in the UK owes much of its baseline risk of electricity peak demand not only to daytime consumption on and off peak, but also to some night consumption. On the contrary, the average Bulgarian, but also Italian, German and Norwegian households present most of the risks of simultaneous electrical appliance usage during the day, and particularly during peak periods.

Work on the risk of peak energy demand has implications on the "low-carbon future" as foreseen by the majority of European Governments [23,24]. Vast portions of energy demand will largely be supplied by renewable sources of energy. Much has been written elsewhere about the risks of renewable generation sources in terms of reliability, intermittency and security of supply [25-27]. A sudden interruption of wind over the Atlantic Ocean could have detrimental impacts on aggregate energy supply in Europe. At the same time, the integration of electric vehicles and heat pumps means that peak demand increases will be disproportionately higher than absolute electricity demand increases. A coherent framework for communicating risks to end-users is currently missing [28], although much technological optimism is placed in smart metering technologies [29].

The relationship between time use and risk of peak energy demand which is analyzed in this paper is not new to risk analysts. Indeed, the concept of peak time and risk is present in various risk-related disciplines, including transport, fire safety and waste. In private investment appraisals risk-benefit models taking into account peak events include insurance claims and peak tariffs for airline companies. In the energy sector the dual component of system level pricing and societal welfare optimisation co-exist.

Climate change is the one factor that is going to intensify the need to address the risk of peak energy demand at policy level. Already the European Commission in Directives 2006/32/EC on energy end-user efficiency (Article 13) and 2005/89/EC on measures to safeguard security of electricity supply 
(Article 5) has emphasised the environmental need for policy intervention in the area of peak demand mitigation. With regards to price, in the future the potential increase in energy prices due to peak events is likely to trigger another policy agenda on fuel poverty. Large socio-demographic datasets on energy consumption are the most frequent types of source used by EU policy-makers for their macroeconomic modelling on the impacts of energy markets [30]. However, these methodological approaches neglect the risk of peak aggregate demand and miss out on the question of when simultaneous congestion takes place. In addition, previous research in the area of the timing of peak energy demand has focused, for instance, on changes to electricity demand load duration curves as a consequence of predicted climate change in Australia [31] and regional-level electricity demand forecasting, but not using time-use data [32]. The methodological approach of this paper (i.e., deriving demand-side risks of peak demand from time-use data) provides an account of typical variations in risks by country, but does not capture seasonal variation, which is a critical factor for understanding the intensity of peaks within a country.

The papers' findings point to the fact that differences in consumption across residential users in a sample of European countries lead to different risks associated with peak demand. This is a paradigmatic shift in the application of risk analysis in the electricity domain-i.e., from risks related to lack of supply due to intermittency to risks associated with surges in residential demand. Connecting time-use survey data with residential electricity load profiles provides analysts with more than just the metered data profiles as it discloses why intraday variation occurred in specific households [33]. The approach and methodology for estimating risk of peak residential electricity demand has potentially useful applications in an interconnected European Supergrid, where reductions in renewable generation have strong regional correlations and the focus shifts to the demand side.

Acknowledgments: This work was supported by the Engineering and Physical Sciences Research Council (grant number EP/P000630/1). The author thanks anonymous reviewers and the Journal editors for their useful comments.

Conflicts of Interest: The author declares no conflict of interest.

\section{Appendix A. Question Coding in Time-Use Diary}

(Q1) What were you doing $x x / x x / x x x x$ at $y y: y y$ ?

\section{RECORD ACTIVITY CODE}

1. Sleeping, resting

2. Washing, dressing

3. Eating at home

4. Cooking, food preparation

5. Care of own children or other adults in own home

6. Cleaning house, tidying, clothes washing, ironing, sewing etc.

7. Maintenance, odd jobs, DIY, gardening, pet care

8. Travel (to and from work, shops, school, cinema, station etc.)

9. Paid work at work place

10. Paid work at home (not using a computer)

11. Study at home (not using a computer)

12. Courses and education outside home

13. Voluntary work, church, helping people (not in own home)

14. Shopping, appointments (hairdressers/doctors etc.)

15. Going to concerts, theatre, cinema, clubs, sporting events

16. Walks, outings etc.

17. Eating out, drinking, (pubs, restaurants) 
18. Visiting or meeting friends or relatives

19. Sports participation, keeping fit

20. Hobbies, games, musical instruments

21. Watching TV/Cable/Satellite TV

22. Watching videos/laser disks

23. Listening to radio, $\mathrm{CD}$, cassette

24. Reading newspapers, books, magazines

25. Being visited by friends or relatives in own home

26. Receiving telephone calls

27. Making telephone calls

28. Personal Computer-games/games console

29. Personal Computer-email (writing, reading or sending)

30. Personal Computer-browsing the www/Internet

31. Personal Computer-study at home

32. Personal Computer-paid work done at home

33. Personal Computer-Other

34. Doing nothing (may include illness)

35. Other PLEASE WRITE IN

(Q2) What time did you finish?

(Q3) What did you do next?

Appendix B. Descriptive Statistics (Values Are Mean Minutes per Day per Person)

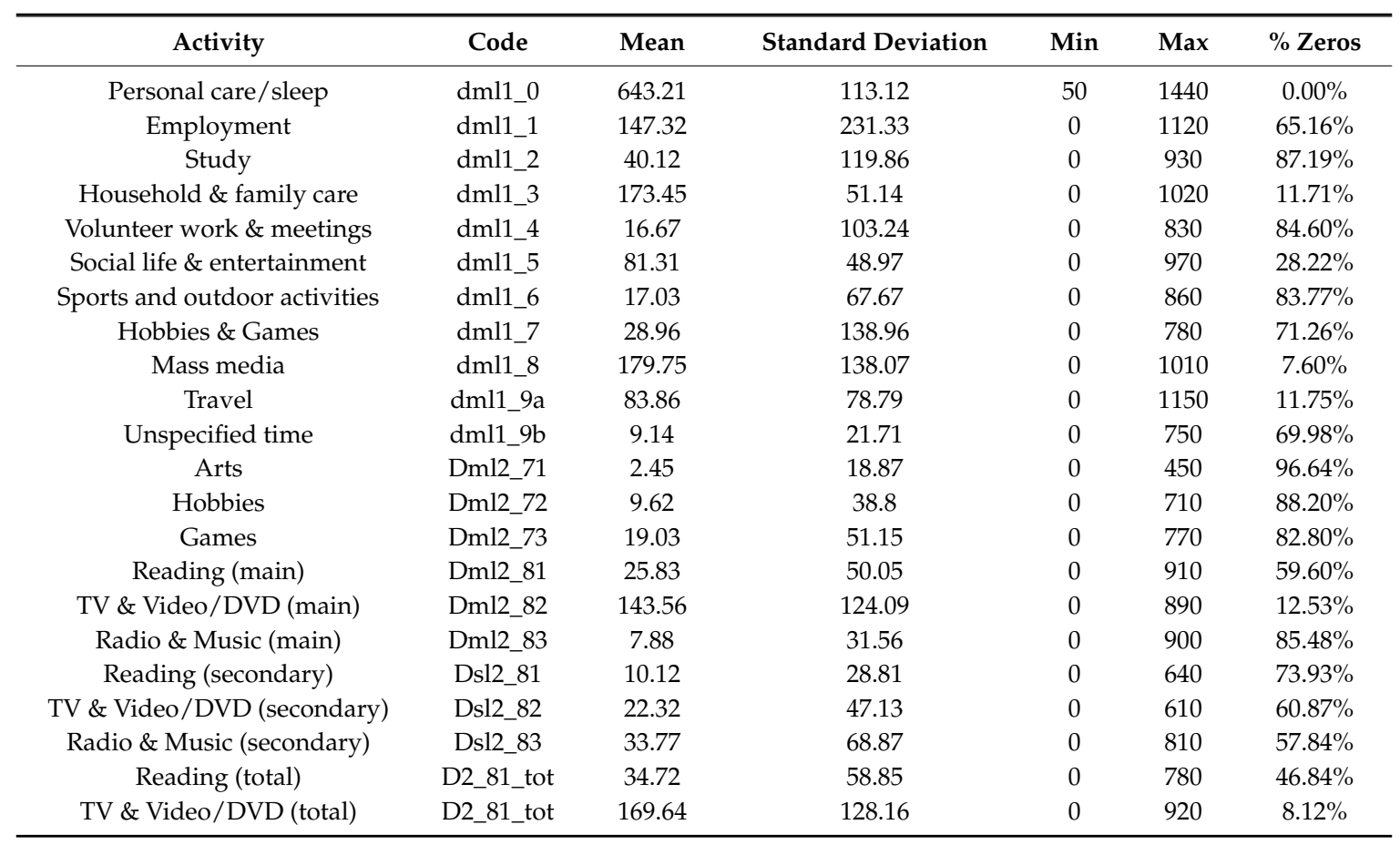

\section{References}

1. Torriti, J. Peak Energy Demand and Demand Side Response; Routledge: London, UK, 2015.

2. Green, R.J.; Lorenzoni, A.; Perez, Y.; Pollitt, M.G. Benchmarking Electricity Liberalisation in Europe. In Electricity Reform in Europe: Towards a Single Energy Market; Glachant, J.M., Leveque, F., Eds.; Edward Elgar: Cheltenham, UK, 2009; pp. 172-204. 
3. Newbery, D.M. Problems of liberalising the electricity industry. Eur. Econ. Rev. 2002, 46, 919-927. [CrossRef]

4. Torriti, J. Impact Assessment and the liberalisation of the EU energy markets: Evidence based policy-making or policy based evidence-making? J. Common Mark. Stud. 2010, 48, 1065-1081. [CrossRef]

5. European Commission. Second Strategic Energy Review: An EU Energy Security and Solidarity Action Plan \{SEC(2008) 2870\} \{SEC(2008) 2871\} \{SEC(2008) 2872\}. 2008. Available online: http:/ /eur-lex.europa.eu/ LexUriServ/LexUriServ.do?uri=COM:2008:0781:FIN:EN:PDF (accessed on 15 March 2017).

6. Gordon, S. Supergrid to the rescue. Power Eng. 2006, 20, 30-33. [CrossRef]

7. Narayanan, A.; Morgan, M.G. Sustaining Critical Social Services during Extended Regional Power Blackouts. Risk Anal. 2011, 32, 1183-1193. [CrossRef] [PubMed]

8. Energy and Climate Change Committee. A European Supergrid: Government Response to the Committee's Seventh Report of Session 2010-12 (HC 1684); Energy and Climate Change Committee: London, UK, 2011.

9. Strbac, G. Demand side management: Benefits and challenges. Energy Policy 2008, 12, 4419-4426. [CrossRef]

10. Widén, J.; Molin, A.; Ellegård, K. Models of domestic occupancy, activities and energy use based on time-use data: Deterministic and stochastic approaches with application to various building-related simulations. J. Build. Perform. Simul. 2012, 5, 27-44. [CrossRef]

11. Richardson, I.W.; Thomson, A.M.; Infield, D. A high-resolution domestic building occupancy model for energy demand simulations. Energy Build. 2008, 40, 1560-1566. [CrossRef]

12. Richardson, I.W.; Thomson, A.M.; Infield, D.; Clifford, C. Domestic electricity use: A high-resolution energy demand model. Energy Build. 2010, 42, 1878-1887. [CrossRef]

13. Widén, J.; Wäckelgård, E. A high-resolution stochastic model of domestic activity patterns and electricity demand. Appl. Energy 2010, 87, 1880-1892. [CrossRef]

14. Widén, J.; Nilsson, A.; Wäckelgård, E. A combined Markov-chain and bottom-up approach to modelling of domestic lighting demand. Energy Build. 2009, 41, 1001-1012. [CrossRef]

15. Torriti, J. Demand Side Management for the European Supergrid: Occupancy variances of European single-person households. Energy Policy 2012, 44, 199-206. [CrossRef]

16. Torriti, J.; Hassan, M.G.; Leach, M. Demand response experience in Europe: Policies, programmes and implementation. Energy 2010, 35, 1575-1583. [CrossRef]

17. ENTSO-E Network Capacity Allocation \& Congestion Management. Available online: https: / / www.entsoe.eu/major-projects/network-code-development/capacity-allocation-and-congestionmanagement/Pages/default.aspx (accessed on 15 March 2017).

18. Vivian, S.; Haslam, K.; Soldner, M.; Sangster, M. Assessment of European energy and carbon profiles of manual and automatic dishwashing. Int. J. Consum. Stud. 2011, 35, 187-193. [CrossRef]

19. Darby, S. The Effectiveness of Feedback on Residential Energy Consumption. A Review for DEFRA of the Literature on Metering, billing and Direct Displays; Environmental Change Institute, University of Oxford: Oxford, UK, 2006.

20. Ehrhardt-Martinez, K.; Donnelly, K.; Laitner, S. Advanced Metering Initiatives and Residential Feedback Programs: A Meta-Review for Household Electricity Saving Opportunities; American Council for an Energy-Efficient Economy: Washington, DC, USA, 2010.

21. Darby, S. Smart Metering: What potential for householder engagement? Build. Res. Inf. 2010, 38, $442-457$. [CrossRef]

22. Tietenburg, T. Economic Instruments for Environmental Regulation. Oxf. Rev. Econ. Policy 1990, 6, 17-33. [CrossRef]

23. Foxon, T.; Hammond, G.; Pearson, P. Developing transition pathways for a low carbon electricity system in the UK. Technol. Forecast. Soc. Chang. 2010, 77, 1203-1213. [CrossRef]

24. Bel, C.Á.; Ortega, M.A.; Escrivá, G.E.; Marín, A.G. Technical and economical tools to assess customer demand response in the commercial sector. Energy Convers. Manag. 2009, 50, 2605-2612.

25. Sinden, G. Characteristics of the UK wind resource: Long-term patterns and relationship to electricity demand. Energy Policy 2007, 35, 112-127. [CrossRef]

26. Balachandra, P.; Chandru, V. Supply demand matching in resource constrained electricity systems. Energy Convers. Manag. 2003, 44, 411-437. [CrossRef]

27. Hammond, G.P.; Waldron, R. Risk Assessment of UK Electricity Supply in a Rapidly Evolving Energy Sector. J. Power Energy 2008, 222, 623-642. [CrossRef] 
28. Spence, A.; Poortinga, W.; Pidgeon, N.F.; Lorenzoni, I. Public perceptions of energy choices: The influence of beliefs about climate change and the environment. Environ. Energy 2010, 21, 385-407. [CrossRef]

29. Fischer, C. Feedback on household energy consumption: A tool for saving energy. Energy Effic. 2008, 1, 79-104. [CrossRef]

30. Torriti, J.; Löfstedt, R.E. The first five years of the EU Impact Assessment system: A risk economics perspective on gaps between rationale and practice. J. Risk Res. 2012, 15, 169-186. [CrossRef]

31. Thatcher, M.J. Modelling changes to electricity demand load duration curves as a consequence of predicted climate change for Australia. Energy 2007, 32, 1647-1659. [CrossRef]

32. Wang, C.-H.; Grozev, G.; Seo, S. Decomposition and statistical analysis for regional electricity demand forecasting. Energy 2012, 41, 313-325. [CrossRef]

33. Torriti, J. A review of time use models of residential electricity demand. Renew. Sustain. Energy Rev. 2014, 37, 265-272. [CrossRef]

(C) 2017 by the author. Licensee MDPI, Basel, Switzerland. This article is an open access article distributed under the terms and conditions of the Creative Commons Attribution (CC BY) license (http:/ / creativecommons.org/licenses/by/4.0/). 